Research Article

\title{
COVID19 and Management Impact of Covid-19 on Education Management in Lebanon
}

\author{
Chirine Khalil NASSAR \\ Faculty of Business Administration, The Bucharest University of Economic Studies, Bucharest, Romania \\ nassar.chirine@gmail.com
}

Received date:11 November 2020; Accepted date: 3 February 2021; Published date: 15 June 2021

Copyright (C) 2021. Chirine Khalil NASSAR. Distributed under Creative Commons Attribution 4.0 International CC-BY 4.0

\begin{abstract}
With the emergence of Covid-19, education management raised eyebrows as schools and universities were the first ones to shift to computer aided learning technologies (CAT) with the vision that learning must never stop. ICT based learning methods have been widely applicable to this date. The study has been conducted to investigate the level of technologies used by instructors, assessment criteria for teachers in distance learning environment, challenges faced by instructors in terms of the integration of teaching technology and lastly challenges faced by students in distance learning programs in Lebanon. In order to investigate these specific objectives, a study has been conducted where primary data has been gathered using questionnaires distributed electronically amongst a sample of 90 students and 90 teachers, using random sampling methods with an adequate ethical consent. Data gathered from questionnaires has been analyzed using descriptive statistics and frequency distribution using Ms Excel. Findings of the study suggest that students in Lebanon are facing numerous issues during their transition from conventional learning to e-learning including accessibility to Internet, Computer, Learning Resources (e.g. Books and Curriculum), Electricity (e.g. Load shedding), Seating Arrangements at Home (e.g. chair, desk, table) and noise distraction at home (e.g. dog barking, child crying). Furthermore, findings suggest that challenges faced by teachers include communicating with school management, electricity disruption, noise distraction challenge, children's participation in online classes, confusion when assessing students' performance, difficulties using ICT based technology, frequent communication with parents, attention distraction and lack of personalized attention. Findings of this study pose significant recommendations for the ministry of education and for school authorities to overcome these issues.
\end{abstract}

Keywords: Covid19, E-learning, Education, Lebanon.

Cite this Article as: Chirine Khalil NASSAR (2021)," COVID19 and Management Impact of Covid-19 on Education Management in Lebanon", Journal of e-Learning and Higher Education, Vol. 2021 (2021), Article ID 284665, DOI: $10.5171 / 2021.284665$ 


\section{Introduction}

The outspread of COVID-19 has created panic, depression and different kinds of anxiety among people across the globe (NCIRD, 2020). The spread of COVID-19 has caused repercussions across the world. Public health calamities, unparalleled in our life spans, have caused acute human sufferings and deaths. The drastic increase in the numbers of infected individuals and its substantial outcomes has stunned hospitals and physicians, putting remarkable pressure on the health division. As governments handled the outspread of the virus by shutting down entire economic divisions and posing formidable extensive limitations on mobility, the health calamity continued to develop into a major financial disaster which is predicted to burden civilizations in the future (Duraku \& Hoxham, 2020). In response to this crisis, there are numerous preventive measures taken by the countries around the world to contain the spread of COVID-19. To save the future generations, schools, colleges and universities have been closed affecting more than 575 million students in 188 countries (UNESCO, 2020).

This has also greatly affected specific categories of people entangled in the education system as they became unable to peruse their education roles in a traditional way, namely classroom environment. As a result of individuals' self-isolation at homes, parents have become worried about their children's educational future (UNESCO, 2020). The reopening of schools and universities has brought undisputable welfares to students and to the broader economy; however, these institutes should be wisely managed against the health hazards and the requisite to alleviate the peal of the pandemic (Schleicher, 2020).

The lockdowns, in reaction to COVID-19, have interrupted the standard schooling system with countrywide school shutdowns in most of the MENA region countries. While the educational community has coordinated efforts to keep up the learning progression during this phase, children and students had to depend on their own means to carry on with learning privately through the Internet, television or radio. Teachers also had to adapt to new educational ideas and methods of teaching, for which, they may have not been prepared. Specifically, learners in the most demoted groups, who don't have access to digital knowledge means, having no elasticity or commitment to seek knowledge on their own, are at danger of tumbling backwards (Schleicher, 2020).

Due to quarantine, the utilization of online learning mechanisms has been considered the most convenient alternative to keep the educational process going in many areas of the globe during the time of the pandemic. Despite the challenges in implementing the online education, there is an urgent need, due to the pandemic, to shift from the traditional way of learning into the distant or online education through applying drastic developmental changes to the discipline of computerized education, which, in other situations, would take a very long time (Lurvnik, 2020). Evidence from Yokozeki (2020) suggests that the shift to distant learning has also been evaluated as a better option for teachers and students to become more powerful, more productive, and improved during the time of self-isolation. On contrary, the current pandemic has raised numerous concerns amongst teachers regarding the teaching procedures that have not been adequately utilized in classrooms before the existing situations (UNESCO, 2020). Additionally, desires for shifting to the online teaching style have also been announced to raise the amount of tension and depression amongst teachers in many parts of the world (Duraku \& Hoxham, 2020). The COVID-19 has also had an acute effect on higher education, as universities shut down their premises and states shut their boundaries as well, in reaction to lockdown precautions. Though colleges and 
universities were quick to replace face-toface lectures with online learning, these closures affected learning and examinations as well as the safety and legal status of foreign students. Significantly, this calamity raises questions about the financial value requested by universities, since they include social prospects and interaction beside the educational content.

\section{Relevancy of Study to Lebanon}

The World Health Organization (WHO), on $30^{\text {th }}$ of January 2020 , declared the Covid-19 outbreak a public health emergency, which subsequently affected education systems worldwide. In Lebanon, the government, on $2^{\text {nd }}$ of March 2020, declared a state of emergency by the issuance of an order to shut down educational institutions within the country to contain the spread of the virus. Both the formal and non-formal education sectors, which include more than 1.2 million children enrolled in formal, nonformal and UNRWA schools, were ordered to shut down their institutions to ensure the safety of future generations. Since the reopening date for these educational institutes was unknown, the Ministry of Higher Education, in Lebanon, launched a distance learning program for schools by proposing a three-point agenda. The first point of the agenda was promoting (a) The use of Electronic Media where the national television and other private media outlets were utilized to spread awareness and provide psychosocial support for learners, parents and caretakers. The second point was promoting (b) The use of internet based online platforms where technologies like Microsoft Teams were integrated with the public school system. However, some private schools use their own platforms. In addition, schools in Lebanon were asked to use online platforms like WhatsApp and Telegram which provided access of learning material to student. Finally, the third point was promoting (c) The utilization of non-ICT methods, which focus mainly on paper-based materials (IAC, 2020).Moreover, IAC (2020) states that MEHE also issued instructions for teachers and academic facilities on guidelines for disseminating lessons and following up with students.

Despite the courageous efforts made by MOHE, in response to the pandemic, the concept of distant learning is still evolving in Lebanon because of the major challenges faced by this online way of learning. Such challenges include electricity disruption across Lebanon, as well as teachers and students' unpreparedness to adapt to new ways of distant learning. In addition, restrictions in movement, as part of the quarantine measures, poses challenges for students to get access to learning resources including stationary and learning tools.

\section{Significance of the Study}

Findings of the study pose significant recommendations for Lebanon which is currently facing many social issues resulting from the civil war, the low public expenditure on education and the influx of refugees. Despite all these challenges, education has emerged as a major national priority for the country. Understanding the learning management in the time of the pandemic will assist the government, particularly the ministry of higher education, in implementing the RACE II plan which emphasizes the inclusive education as part of its commitment towards sustainable development goals.

\section{Research Question}

- What is the level of technologies used by instructors in Lebanon?

- What are the assessment criteria for teachers in the distance learning environment in Lebanon?

- What are the challenges faced by instructors in the integration of teaching technology in Lebanon?

- What are the challenges faced by students in distance learning programs in Lebanon? 


\section{Methodology}

Research philosophy refers to the belief which provides insights on how data shall be collected, analyzed and used reliably to achieve research outcomes. Within the scope of the current research, research philosophy can be categorized into four different types which include (a) pragmatism, (b) positivism, (c) realism and (d) interpretivism. The researcher intends to make a choice between positivism and interpretivism which are traditionally represented using quantitative and qualitative research methods. The study uses the positivist research philosophy where high structured data will be gathered from participants which incorporate large sample respondents. The study uses quantitative research design which aims to explore the respondent's perspectives of the challenges faced by the distance education system, which is essential from education management perspective (Saunders et al., 2009).

Backed by the positivist research philosophy, the research design provides a plan for the collection, measurement and analysis of data. The study intends to use descriptive research design which is based upon the statistical research which describes the phenomenon as it exists (Akhtar, 2016). The descriptive research design aims to measure where, when and how the phenomenon occurs by investigating the challenges faced by distance learning and the education industry as a whole. The study aims to investigate the perspectives of teachers, academics and learners. Therefore, the primary data has been gathered from learners engaged in distance learning and teachers involved in curriculum management and curriculum delivery using internet based technologies. It is noteworthy to examine the phenomenon in detail by describing the concerns of relevant stakeholders which include teachers and learners who are engaged in remote and online learning caused by social isolation.
Primary data will be gathered using questionnaires as the author intends to distribute two separate sets of questionnaires, the first one for teachers which aims to cover key areas like (a) level of technology used by instructors in Lebanon in post covid-19 times, (b) method of online learning, (c) assessment of students' performance in remote learning and (d) challenges faced by teachers in the implementation of remote learning. Similarly, another set of questionnaires will be distributed amongst students to investigate the (a) possession of adequate technological equipment and (b) challenges faced by learners (Al-Jammal \& Ghamrawi, 2013). Questionnaires will be used as an instrument where the questionnaire items, for each category of the respondents, will be developed using a close ended instrument using Thurston scale. Questionnaire items on challenges faced by students have been adapted from the previous studies of Senthilkumar \& Kumari (2020). Lastly, questionnaire items on challenges faced by teachers have been adapted from the previous studies of Duraku \& Hoxha, (2020).

The scope of the study revolves around school students who were the first to experience distant learning programs in Lebanon as per MEHE's guidelines. According to CERD, (2020) the number of school students who are currently enrolled in private schools, public schools and private free schools is 942 thousand. There are 497,530 students registered in public schools and 285339 in private schools in Lebanon. The remaining 159462 students are enrolled in private free schools. The total sample size of 90 students will be targeted by the author using the cluster based sampling method where an equal amount of respondents will be targeted from the cluster of public, private and private free schools across Lebanon. The scope of the study requires the author to incorporate the opinion of teachers. According to the World Bank (2020), there are more than 80 thousand people who are associated with the teaching profession in Lebanon. The current study aims to target 90 
teachers working in public, private and private free schools across Lebanon, using the cluster based sampling technique.

Data collected from questionnaires will be analyzed using descriptive statistics and frequency distribution where pie charts will be used based upon the distribution of responses across frequency, providing the rationale for the analysis and discussion.

\section{Findings}

\section{Demographics of Students}

Students from different parts of Lebanon, namely Halba, Baalbek, Beirut, Zahlé, Baabda, Nabatieh, Tripoli and Sidon were targeted in the survey. Out of a total sample of 90 respondents, 37 respondents (41.1\%) were males, whereas the remaining 53 respondents (58.9\%) were females.

Students from different family backgrounds were targeted in the survey. 44 respondents $(48.9 \%)$ were reported having 1 to 3 family members, 31 respondents (34.4\%) were reported having 4 family members, and the remaining 15 respondents (16.7\%) were reported having more than 6 family members.

Respondents from different categories of schools were targeted in the survey by the author. 30 participants (33.3\%) belong to the public school system in Lebanon, 30 respondents $(33 \%)$ belong to the private school system in Lebanon, and the remaining 30 respondents (33.3\%) belong to the private free school system in Lebanon.

Students enrolled in different public, private and free private schools were asked whether they enjoy distance learning programs provided by their institutes. 62 respondents $(68.2 \%)$ reported that they enjoy learning from home, 8 respondents $(8.9 \%)$ reported that they don't enjoy learning from home. Lastly, 20 respondents $(22 \%)$ reported that they are not sure whether they enjoy learning from home using distance learning technologies during the period of lockdown and restrictive movement or not.

Respondents of the study were enquired about the technology being used by their schools for online education. The majority of the respondents, which represents $61.1 \%$ (55) of the respondents, reported that they use Google Classroom for attending their daily classes during the lock down period in Lebanon, $21.1 \%$ (19) of the respondents reported that they use Zoom for attending their classes. $14.4 \%$ of the respondents reported that they use Microsoft Teams. Lastly, 3.3\% of the respondents reported that they use other software applications to access their virtual classroom and learning resources.

Respondents of the study were asked about the technology being used by their school administration to share curriculum related information. 45 respondents (50\%) reported that the majority of the schools used an elearning system which can be accessed using students' credentials, 29 respondents (32\%) reported that their school used WhatsApp to share curriculum related information, 8 respondents (8.9\%) reported that curriculum related information is shared via email with parents, and the remaining $8.9 \%$ of the respondents reported using other media for sharing curriculum related information.

\section{Challenges Faced by Students}




\section{Challenges Faced by Students in Education Management}

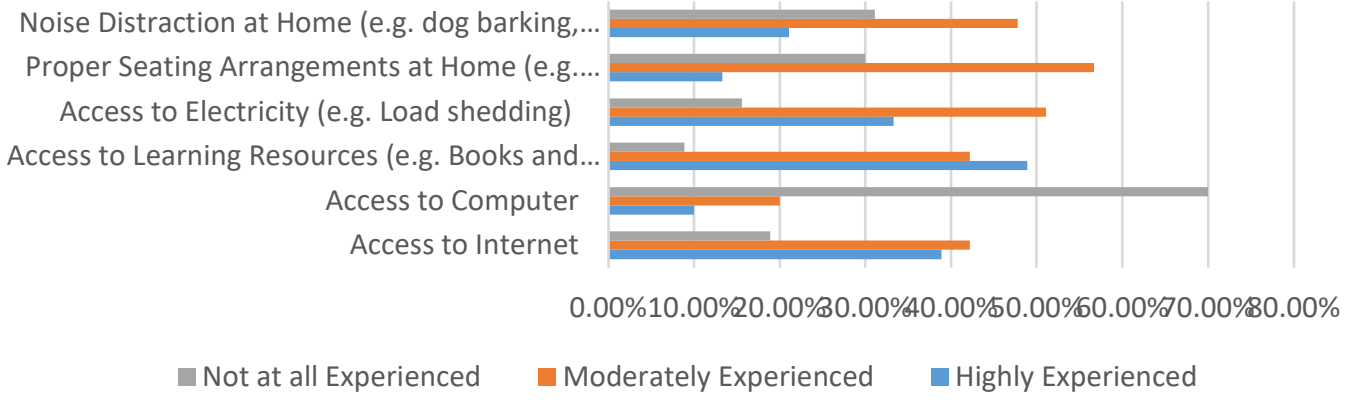

0.00\%10.00\%20.00\%0.00\%0.00\%0.00\%60.00\%0.00\% $80.00 \%$

Not at all Experienced $\square$ Moderately Experienced $\quad$ Highly Experienced

\section{Figure 1: Challenges Faced by Students}

Respondents were asked about the challenges faced by students during distance learning. $42.2 \%$ reported that noise distraction i.e. (dog barking and children crying) was moderately experienced during online learning at home. $56.7 \%$ of the participants reported having moderately experienced issues of proper learning environment at home which includes having adequate furniture and desks during their online learning sessions. $51 \%$ of the respondents reported having moderately experienced issues of access to electricity which disrupts their learning experience at home causing internet disruption. $48 \%$ of the respondents reported having highly experienced issues of access to learning resources at home. The majority of the respondents, which represents $70 \%$ of the students, have not at all experienced issues related to the accessibility of personal computers, tablets, phones and laptops. Lastly, $42 \%$ reported having moderately experienced issues of internet disruption in some parts of Lebanon.

\section{Challenges Faced by Teachers}

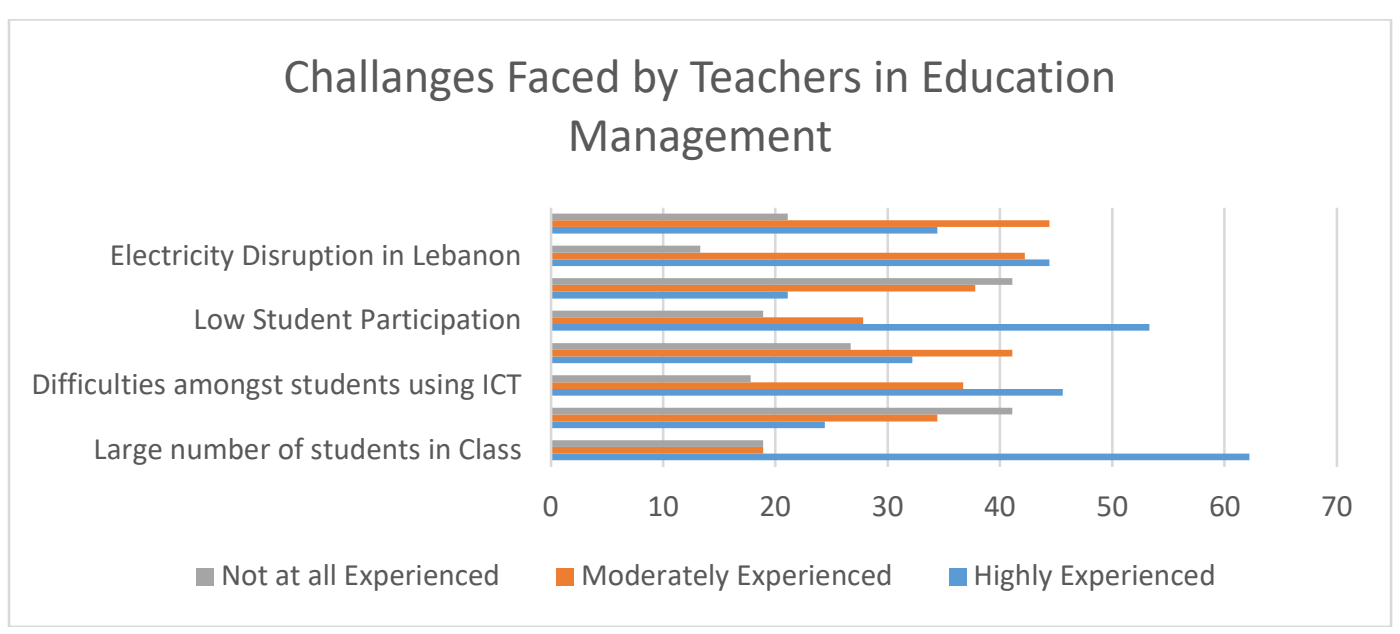

Figure 2: Challenges Faced by Teachers in Education Management 
The second questionnaire was distributed among teachers working in different private, public and private free schools across Lebanon. Respondents were targeted with key questions. The majority of the teachers, which represents $44.2 \%$ of the respondents, reported that they have moderately experienced issues in communicating with school management during the tenure of working at home in times of lockdown. Respondents of the study were asked about electricity disruption as a challenge facing distance learning opportunities in Lebanon, $44.4 \%$ of the teachers reported that they have highly experienced load shedding and power shortages which have disrupted the distance learning experience due to internet connectivity issues. Teachers were enquired about the noise disruption challenge faced by them, and the majority of the respondents, which includes $41.1 \%$ of the respondents, reported that they have not at all experienced such issues during distance learning at home. Teachers were asked about the challenges related to children's participation in online classes, where 53.3\% reported that they have highly experienced issues of children's participation in terms of absenteeism amongst students attending online sessions at home. $41.1 \%$ of the teachers reported that they have moderately experienced issues like confusion when assessing students' performance. $45.6 \%$ of the respondents reported that they believe that many students face difficulties using ICT based technology. $41.1 \%$ of the respondents reported that they have not at all experienced issues of frequent communication with parents. Lastly, $62.2 \%$ of the teachers reported having a large number of students in the online classes, which poses challenges such as attention distraction and lack of personalized attention to each student caused by the large size of the online class.

\section{Discussion}

This study aimed to examine the impact of the COVID-19 outbreak on education management and evaluate significant challenges facing online learning in Lebanon where e-learning courses are not common. Thus, this study clarifies, through both the research and practice, which elements to pay special attention to when designing online learning schemes during this situation.

Findings of the study suggest that most commonly occurred challenges faced by students in Lebanon, as a result of the transition from conventional learning to elearning, include accessibility to Internet, Computer, Learning Resources (e.g. Books and Curriculum), Electricity (e.g. Load shedding), Seating Arrangements at Home (e.g. chair, desk, table) and noise distraction at home (e.g. dog barking, child crying). Empirical evidence from Aboagye (2020) shows a similar trend investigating the challenges faced by tertiary institutions in the time of lockdown. The findings of the study suggest that the most common issues faced by institutes include social issues, accessibility issues, motivation, and academic issues. Findings validate those of a previous study conducted by Raju (2020), which suggest that internet accessibility is amongst the major issues faced by students, as many of the students don't have good connectivity to $4 \mathrm{G}$ networks in the rural parts of the country, resulting in problems like buffering during the live streaming of the online lectures. Furthermore, Raju's (2020) findings show that access to resources, like books, is the biggest challenge facing students, as many students had to leave hostels and PGs immediately after the lockdown and could no longer carry textbooks and course materials. Andersson (2020) adapted a holistic approach by categorizing those challenges into numerous types including students, technology, institution, teachers, and support. The findings of the Andersson's (2020) study show that the most commonly incurred challenges faced by students during the Covid-19 lockdown include motivation, conflicting priorities, confidence, learning styles, and accessibility. Sarvestani et al.'s (2020) findings show that infrastructure 
issues are one of the most significant challenges faced by students during Covid19 , amongst which the most commonly incurred challenges include internet connectivity issues, scarcity of physical space to pursue virtual education, lack of access to school resources, lack of facilities and disconnectivity issues.

For the facilitators, it is very hard to understand the online learning attitudes since it meant coping with some flaws. Elearning is a good option in an unrealistic optimistic situation (like COVID-19), but it does not seem to be 'as good as' conventional face-to-face learning (Andersson, 2008). The physical classroom environment and face-toface interaction between students and teachers give satisfactory learning outcomes. Students work in a group, helping one another to accomplish assignments and semester projects. Moreover, during lectures, professors' facial gestures and ways of describing a specific point play an important role to facilitate learning. Unfortunately, during the online classes, these things are negligible (Aboagye, Yawson, \& Appiah, 2020). However, developing the e-learning system contributes to the excellence of the educational system. E-learning is the secondbest option for education institutes, because during the current pandemic situation, students' learning process proceeded and students are able to continue their semester without wasting their learning time. Thus, comprehending the difficulties and barriers of establishing e-learning in higher education institutions, and offering practical solutions for them (Sarvestani, Mohammadi, Afshin, \& Raeisy, 2019) are the current needs to cope with the pandemic situation. During the COVID-19 lockdowns, virtual platforms not only served the education facilities in terms of students, but also offered many short-term certificate courses, as well as different development courses offered to the teaching staff too by many institutes (Raju, 2020).

\section{Conclusion}

It is important to address all the challenges of the pandemic situation. This study is significant as it engages students in learning activities and keeps them active and busy with studies. For example, the combined approach ought to have students guided to elearning before making any changes to the elearning system. For students, especially for school-going students, e-learning is a completely new concept and that's why, in the pandemic situation, they faced many issues to learn from the virtual platform. Also, most of the university students preferred to put their current semester on hold till further notice. Thus, it is necessary to consider all these problems before the implementation of e-learning in higher education establishments in Lebanon.

Future Research Agenda

Future studies should analyse these factors in-depth, investigate the student's e-learning experience after the COVID-19 lockdown, examine the consequences of e-learning, and examine the impact of the pandemic on education in an underdeveloped nation.

\section{Survey For Students}

This questionnaire examines your preferences about distant learning during covid-19 lockdown in Lebanon. The questionnaires aim to investigate (a) the level of technology used by students and (b) the challenges faced by students. Your participation in the survey is completely voluntarily and your response will benefit the researcher and the authorities in improving the distance learning experience. 
What is your gender?

Male $\square$ Female $\square$

Number of family members?

$1-3 \square$ 4-6 $\square$ More than 6

Specify the category of your school?

Private School $\square$ Public School $\square$ Private Free School

Do you enjoy working from home during Covid-19 lockdown?

Yes $\square$ No $\square$ Maybe

What are the technologies being used by your school for online/distance education?

Microsoft Teams $\square$ Zoom $\square$ Google Classroom $\square$ others

What are the technologies used by school's administration to share curriculum related information?

E-Learning System $\square$ WhatsApp $\square$ Email $\square$ others

Rate Challenges Faced in Accessing School Distance Learning Programs

\begin{tabular}{|l|l|l|l|}
\hline Challenges & Highly Experienced & $\begin{array}{l}\text { Moderately } \\
\text { Experienced }\end{array}$ & $\begin{array}{l}\text { Not at all } \\
\text { Experienced }\end{array}$ \\
\hline Access to Internet & & & \\
\hline Access to Computer & & & \\
\hline $\begin{array}{l}\text { Access to Learning } \\
\text { Resources (e. g. Books } \\
\text { and Curriculum) }\end{array}$ & & & \\
\hline $\begin{array}{l}\text { Access to Electricity (e. } \\
\text { g. Load shedding) }\end{array}$ & & \\
\hline $\begin{array}{l}\text { Proper Seating } \\
\text { Arrangements at } \\
\text { Home (e. g. chair, desk, } \\
\text { table) }\end{array}$ & & & \\
\hline
\end{tabular}

\section{Survey For Teachers}

This questionnaire examines your preferences about distant learning during covid-19 lockdown in Lebanon. The questionnaires aim to investigate (a) the level of technology used by students and (b) the challenges faced by students. Your participation in the survey is completely voluntarily and your response will benefit the researcher and the authorities in improving the distance learning experience. 


\section{What is your gender?}

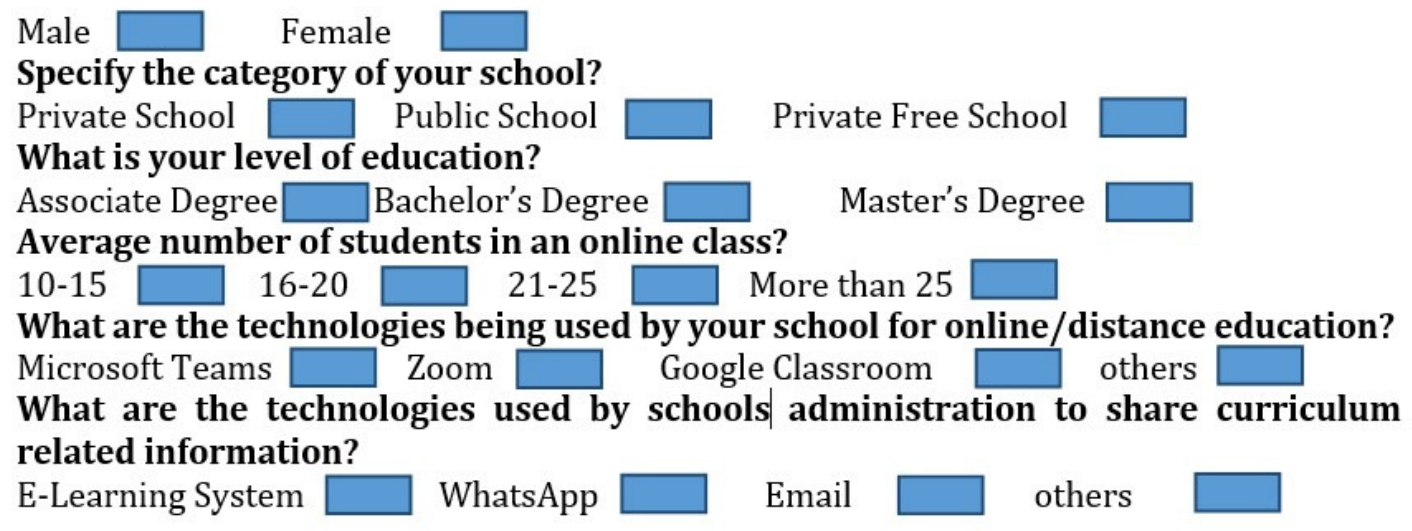

\section{Rate Challenges Faced in Accessing School Distance Learning Programs}

\section{References}

- Al-Jammal, K., \& Ghamrawi, N. (2013). Teacher professional development in Lebanese schools. Journal of Education Research and Review, 2(7), 104128. https://www.researchgate.net/publicat ion/287996741_Teacher_professional_dev elopment_in_Lebanese_schools

- Aboagye, E., Yawson, J. A., \& Appiah, K. N. (2020). COVID-19 and E-Learning: the Challenges of Students in Tertiary Institutions. Social Education Research, 2(1), 1-8. doi:org/10.37256/ser.212021422

- Andersson, A. (2008). Seven Major Challenges for E-Learning in Developing Countries Case Study eBIT, Sri Lanka. International Journal of Education and Development using ICT, 4, 46-62.

- Duraku, Z. H., \& Hoxha, L. (2020). The impact of COVID-19 on education and on the well-being of teachers, parents, and students: Challenges related to remote (online) learning and opportunities for advancing the quality of education. Journal of Education, 2(3), 110. https://www.researchgate.net/publicati on/341297812_The_impact_of_COVID19_on_education_and_on_the_wellbeing_of_teachers_parents_and_students_ Challenges_related_to_remote_online_lear ning_and_opportunities_for_advancing_th e_quality_of_education

- IAC. (2020). EDUCATION SECTOR SHORT-TERM RESPONSE TO COVID19

LEBANON. IAC. https://resourcecentre.sa vethechildren.net/node/17654/pdf/76675.p df

- Lurvnik: UNESCO. (2020, March 30). COVID-19 Webinar: A new world for teachers, education's frontline workers. Marrë https://en.unesco.org/news/covid-19webinar-new-world-teachers-educationsfrontline-workers

- NCIRD, (2020). Coronavirus Disease 2019. National Center for Immunization and Respiratory Diseases (NCIRD). Division of Viral Diseases. Marre nga: https://www.cdc.gov/coronavirus/2019ncov/daily-life-coping/managing-stressanxiety.html

- Raju, H. (2020). Covid -19 LockdownChallenges to Higher Education. An International Multidisciplinary DoubleBlind Peer-reviewed Research Journal, 2(4). doi:10.13140/RG.2.2.16290.25281

- Saunders, M. N., LEwis, P., \& Thornhill, A. (2009). Understanding research philosophies and approaches.https://www.researchgate.net/p ublication/309102603_Understanding_res earch_philosophies_and_approaches

- Sarvestani, M. S., Mohammadi, M., Afshin, J., \& Raeisy, L. (2019). Students' Experiences of E-Learning Challenges; a 
Phenomenological Study. Interdisciplinary Journal of Virtual Learning in Medical Sciences, 10(3), 1-10.

- Schleicher, A. A. (2020). The Impact of Covid-19 On Education Insights From Education At A Glance 2020. OECD. https://www.oecd.org/education/theimpact-of-covid-19-on-education-insightseducation-at-a-glance-2020.pdf

- Senthilkumar, S., \& Kumari, K. (2020). Impact Of Coronavirus On Education: Stay Away From Schools And Colleges. Alochana Chakra Journal, 9(7), 3440-

3449. https://www.researchgate.net/public ation/342716335_IMPACT_OF_CORON
AVIRUS_ON_EDUCATION_STAY_A WAY_FROM_SCHOOLS_AND_COLLE GES

- UNESCO (2020). Covid-19 Impact on Education Data. COVID-19 Education Disruption and Response. The United Nations Educational, Scientific and Cultural Organization, UNESCO. Paris, France

- Yokozeki: UNESCO. (2020, March 30). COVID-19 Webinar: A new world for teachers, education's frontline workers. Marrëngahttps://en.unesco.org/news/covid -19-webinar-new-world-teacherseducations-frontline-workers 